\title{
Postprandial Endotoxin Transporters LBP and sCD14 Differ in Obese vs. Overweight and Normal Weight Men during Fat-Rich Meal Digestion
}

\author{
Fabienne Laugerette ${ }^{1, *}$, Cécile Vors ${ }^{1}$, Maud Alligier ${ }^{1,2}{ }^{-}$, Gaëlle Pineau ${ }^{1}$, Jocelyne Drai ${ }^{1,3}$, \\ Carole Knibbe $^{1}$, Béatrice Morio ${ }^{1,2}$, Stéphanie Lambert-Porcheron ${ }^{2,4}$, Martine Laville ${ }^{1,2,4}$, \\ Hubert Vidal ${ }^{1,2,4}$ and Marie-Caroline Michalski ${ }^{1,2}$ \\ 1 Univ Lyon, CarMeN Laboratory, INRAE, UMR1397, INSERM, UMR1060, Université Claude Bernard Lyon 1, \\ 69310 Pierre Bénite, France; cecile.vors@univ-lyon1.fr (C.V.); maud.alligier@chu-lyon.fr (M.A.); \\ gaelle.pineau@gmail.com (G.P.); jocelyne.drai@gmail.com (J.D.); carole.knibbe@insa-lyon.fr (C.K.); \\ beatrice.morio@clermont.inra.fr (B.M.); martine.laville@univ-lyon1.fr (M.L.); \\ hubert.vidal@univ-lyon1.fr (H.V.); marie-caroline.michalski@insa-lyon.fr (M.-C.M.) \\ 2 Centre de Recherche en Nutrition Humaine Rhône-Alpes, Univ-Lyon, CarMeN Laboratory, Université \\ Claude Bernard Lyon1, Hospices Civils de Lyon, CENS, FCRIN/FORCE Network, 69310 Pierre-Bénite, \\ France; stephanie.lambert-porcheron@chu-lyon.fr \\ 3 Laboratoire de Biochimie, Centre Hospitalier Lyon Sud, 69600 Oullins, France \\ 4 Hospices Civils de Lyon, 69000 Lyon, France \\ * Correspondence: fabienne.laugerette@univ-lyon1.fr; Tel.: +33-4-26-23-61-74
}

Received: 29 April 2020; Accepted: 15 June 2020; Published: 18 June 2020

check for updates

\begin{abstract}
Circulating levels of lipopolysaccharide-binding protein (LBP) and soluble cluster of differentiation 14 (sCD14) are recognized as clinical markers of endotoxemia. In obese men, postprandial endotoxemia is modulated by the amount of fat ingested, being higher compared to normal-weight (NW) subjects. Relative variations of LBP/sCD14 ratio in response to overfeeding are also considered important in the inflammation set-up, as measured through IL-6 concentration. We tested the hypothesis that postprandial LBP and sCD14 circulating concentrations differed in obese vs. overweight and NW men after a fat-rich meal. We thus analyzed the postprandial kinetics of LBP and sCD14 in the context of two clinical trials involving postprandial tests in normal-, over-weight and obese men. In the first clinical trial eight NW and 8 obese men ingested breakfasts containing 10 vs. $40 \mathrm{~g}$ of fat. In the second clinical trial, 18 healthy men were overfed during 8 weeks. sCD14, LBP and Il-6 were measured in all subjects during $5 \mathrm{~h}$ after test meal. Obese men presented a higher fasting and postprandial LBP concentration in plasma than NW men regardless of fat load, while postprandial sCD14 was similar in both groups. Irrespective of the overfeeding treatment, we observed postprandial increase of sCD14 and decrease of LBP before and after OF. In obese individuals receiving a $10 \mathrm{~g}$ fat load, whereas IL-6 increased 5h after meal, LBP and sCD14 did not increase. No direct association between the postprandial kinetics of endotoxemia markers sCD14 and LBP and of inflammation in obese men was observed in this study.
\end{abstract}

Keywords: LBP; sCD14; postprandial kinetics; high-fat diet

\section{Introduction}

Metabolic diseases, including obesity and type 2 diabetes, are associated with a chronic inflammatory state and increased plasma levels of lipopolysaccharides (LPS), also called endotoxins [1]. Endotoxins are components of the outer membrane of Gram-negative bacteria, which are dominant in the healthy human gut microbiome [1]. During lipid digestion, some endotoxins are translocated 
in the bloodstream, and thereby contribute to the onset and maintenance of low-grade inflammation during the postprandial phase following a fat-rich meal [2-5]. Indeed, Clemente-Postigo et al. (2012) reported an increase in the plasma level of endotoxins after a fat overload in morbidly obese humans [6]. This includes the binding of LPS to LPS-binding protein (LBP) and its transfer to the receptor CD14, present in both soluble (sCD14) and membrane-bound (mCD14) forms [7]. The activation of the LPS-LBP-CD14 complex leads to the secretion of pro-inflammatory markers and contributes to the inflammatory state [8]. LBP and SCD14 are now recognized as clinical markers of endotoxin exposure [9] and have been associated with obesity and metabolic disorders [10]. LBP is synthesized and released into the bloodstream in the presence of LPS, and is considered as a surrogate biomarker for the activation of LPS-induced innate immune response regarding its relative long half-life (24-48 h) [11]. Moreno-Navarrete et al. have also shown that the increase of plasma LBP in vivo may contribute to a vicious cycle that prevents white adipose tissue (WAT) expansion, and exacerbates the inflammatory response in WAT [12]. It was further shown that serum LBP and sCD14 are markers of Crohn's disease [13]. The relative variations of LBP/sCD14 ratio are also considered important in the inflammation set-up [14]. Furthermore, higher plasma LBP concentrations have been observed in obesity $[7,13,15]$ and plasma LBP concentration is associated to abdominal obesity [16]. We have recently shown that increase of plasma IL-6 is linked to a rise of LBP/sCD14 ratio in both humans [14] and mice [17]. More recently, Sakura et al. have suggested that plasma LBP concentration is associated with arterial stiffness, independently of traditional cardiovascular risk factors and especially in men with type 2 diabetes $[18,19]$. In children and adults, obesity and obstructive sleep apnea are also associated with increased LBP concentrations, and the presence of both conditions may enhance LBP concentration $[20,21]$. Concerning sCD14, it has been reported in mice that SCD14 presents protective effects in inflammatory bowel disease [22]. Therefore, the literature shows that LBP and sCD14 are important factors implicated in low-grade inflammation during metabolic diseases. We have previously demonstrated in obese men that postprandial endotoxemia is modified by ingested fat amount with a higher postprandial endotoxemia compared with normal-weight subjects after a higher fat load ( $40 \mathrm{~g}$ vs. $10 \mathrm{~g}$ ) [23]. More recently, a study of healthy premenopausal women has suggested that the consumption of a pre-meal yogurt improves the postprandial metabolism and decreases metabolic endotoxemia, LBP and sCD14 [24]. However, the postprandial variations of LBP and sCD14 after a mixed meal with different amount of lipids remain poorly described in humans of different weight status. We thus analyzed the postprandial kinetics of both markers of endotoxin exposure in the context of two clinical trials involving postprandial tests in normal weight, overweight and obese men. We hypothesized that postprandial LBP and sCD14 after a fat-rich meal differed in obese vs. overweight and normal weight men, hence, contributing to different IL-6 responses after a fat load or OF.

\section{Materials and Methods}

\subsection{Clinical Trials and Subjects}

The present work relies on two previous clinical trials performed in the Human Nutrition Research Centers (CRNH) of Rhône-Alpes and Auvergne. The first clinical trial, called the Lipinflox study, was approved by the Ethics Committee of Lyon-Sud-Est-II and AFSSAPS and was registered at ClinicalTrials.gov (NCT01249378). The second one, called the Overfeeding Study, was approved by the Ethics Committee of Lyon (RG/FL-2005-067) and registered at clinicalTrials.gov (NCT00905892). The eligibility criteria of included subjects and postprandial metabolic explorations for both trials have been described elsewhere $[23,25,26]$. Briefly, in the crossover Lipinflox Study, 8 normal weight $(20$ $<$ BMI $\left.<25 \mathrm{~kg} / \mathrm{m}^{2}\right)$ and 8 obese $\left(30<\mathrm{BMI}<35 \mathrm{~kg} / \mathrm{m}^{2}\right.$ and waist circumference $\left.>94 \mathrm{~cm}\right)$ men were submitted to a fat load of $10 \mathrm{~g}$ or $40 \mathrm{~g}$ at breakfast. The test breakfast contained 10 or $40 \mathrm{~g}$ of anhydrous milk fat with bread and a glass of skim milk ( $282 \mathrm{kcal}$ and $551 \mathrm{kcal}$, respectively). Blood samples were collected from an antecubital arm vein through a catheter at baseline and at regular intervals during 
$5 \mathrm{~h}$, following ingestion of fat load. Plasma was separated by centrifugation $\left(1500 \mathrm{~g}, 10 \mathrm{~min}, 4{ }^{\circ} \mathrm{C}\right)$ and stored at $-80^{\circ} \mathrm{C}$ until further analysis. In the overfeeding clinical trial, 18 healthy young men (lean to overweight, BMI $25.8 \pm 0.8 \mathrm{~kg} / \mathrm{m}^{2}$, age $30.6 \pm 2.1$ years) were submitted to an overfeeding during 56 days. During this period, the subjects added to their daily diet $+760 \mathrm{kcal} /$ day as previously described [25]. Fasting plasma sampling was performed at Day 0 and Day 56. In this article, we focused on a subcohort of eight subjects that consumed a test meal $(882 \mathrm{kcal})$ and performed a postprandial test including endotoxemia analyses, as described previously [25]. The mixed meal contained $33 \mathrm{~g}$ of fat $(291 \mathrm{kcal})$ and was composed of $200 \mathrm{~mL}$ of Fortimel (enteral emulsion), $23 \mathrm{~g}$ of margarine, $9.4 \mathrm{~g}$ of butter, $1 \mathrm{~g}$ of olive oil, $85 \mathrm{~g}$ of bread, $20 \mathrm{~g}$ of jam and $200 \mathrm{~g}$ of banana. The body composition (fat and lean mass) was performed in 18 subjects. All subjects gave written consent after being informed of the nature, purpose, and possible risks of the clinical trial. Both clinical trials were approved by the ethics committee of Lyon Sud-Est, according to the French"Huriet-Serusclat" law and the Second Declaration of Helsinki.

\subsection{Plasma SCD14 and LBP}

To measure the plasma concentrations of circulating LBP and sCD14, plasma samples were assayed using sandwich ELISA kits (CliniSciences and R\&D Systems; Nanterre, France), following the manufacturer's instructions.

\subsection{Plasma Analyses}

Endotoxins were determined using the limule amoebocyte lysate assay in kinetic chromogenic conditions (Biogenic; Pérols, France) [15]. Serum high-sensitive C-reactive protein was assessed by immunonephelometry on an image analyzer (Beckman-Coulter; Villepinte, France). For the overfeeding trial, IL-6 was measured in serum using ELISA kits (Quantikine; Abingdon, UK). For Lipinflox, plasma hsIL-6 levels were measured using a sandwich Ultrasensitive ELISA kit (Invitrogen; Illkirch, France). The liver enzymes ASAT and ALAT were routinely measured during the screening visit (Pentra C400; Horiba, Kyoto, Japan) in order to exclude patients if the values were not biologically normal. In fact, as patients were submitted to a fat load, or to an overfeeding, it was important that they had no liver disease.

\subsection{Anthropometry and Body Composition}

As previously described by Alligier et al., body composition was determined before and after overfeeding by dual-energy X-ray absorptiometry (Hologic, Inc.; Bedford, MA, USA), and abdominal adipose tissue distribution by magnetic resonance imaging (Magnetom Symphonie 1.5 Tesla; Siemens AG, Munich, Germany) [25].

\subsection{Statistical Analysis}

Data are presented as means \pm SEM and were analyzed with Graph Pad Prism ${ }^{\circledR}$ (version 7.0, San Diego, CA, USA) and with R (version 3.6.3, Saint Louis, USA). Clinical characteristics of the subjects of the two clinical trials (before vs. after overfeeding and lean vs. obese subjects) were performed using Student's $t$-test with Graph Pad Prism. To evaluate possible relationships among the various outcomes, Spearman correlations were performed using Graph Pad Prism Software. For the Overfeeding Study, postprandial kinetics of plasma LBP, sCD14, LBP/sCD14 ratio and IL-6 were each analyzed by two-way ANOVA for repeated measurements in both factors (time and overfeeding), followed by Bonferroni's post hoc test, using Graph Pad Prism. For the Lipinflox study, postprandial kinetics of plasma LBP, sCD14 and IL-6 were each analyzed with a linear mixed-effects model, analogous to a 3-way ANOVA for repeated measurements, where the factors with fixed effects were time, obese status, fat load and their 2- and 3-way interactions, while the factor with random effects was the subject identifier. This analysis was carried out with $\mathrm{R}$, using the lme function of the nlme package. The main effects and the interactions effects were tested using marginal (Type III) sums of squares like in GraphPad 
Prism. For the Lipinflox study, postprandial kinetics of plasma LBP, sCD14 and IL-6 were each analyzed with a linear mixed-effects model, where the factors with fixed effects were time, obese status, fat load and their 2- and 3-way interactions, while the factor with random effects was the subject identifier. This approach is similar to a three-way repeated-measures ANOVA but is more robust to missing data (we lacked IL6 data for one of the ten lean subjects). A posthoc analysis was carried out to assess the effect of obesity on the estimated marginal means at all time points. Specifically, the significance of the difference of the two marginal means (lean versus obese, collapsing the fat load) was assessed at each time point with a $t$-test based on the standard errors of the estimated marginal means. The five raw $p$-values obtained for each response in this posthoc analysis were adjusted using the False Discovery Rate (FDR) correction, in order to correct for multiple testing. This posthoc analysis was carried out with the emmeans package. A $p$-value (or a FDR-corrected $p$-value) lower than 0.05 was considered significant.

\section{Results}

\subsection{Characteristics of the Subjects}

The characteristics of the eight subjects, lean to overweight, from the overfeeding clinical trial (OF) and from the 16 subjects (normal weight and obese) from Lipinflox clinical trial are shown Table 1. As expected weight, BMI and waist circumference were significantly higher after OF, compared to before, and higher in the obese than in normal weight (NW) subjects. Concerning body composition, lean mass and fat mass were significantly enhanced after OF. CRP, IL-6 and LPS did not vary significantly in the OF clinical trial. CRP and IL-6 were higher in obese compared to NW subjects.

Table 1. Clinical characteristics of study subjects. Data are means \pm SEM. Groups are compared using unpaired Student $t$-test, ${ }^{*} p<0.05,{ }^{* *} p<0.01 ; n=8$ OF clinical trial, $n=8$ normal weight, $n=8$ obese.

\begin{tabular}{|c|c|c|c|c|c|c|}
\hline & \multicolumn{3}{|c|}{ Overfeeding Clinical Trial } & \multicolumn{3}{|c|}{ Lipinflox Clinical Trial } \\
\hline & Before OF & After OF & $p$ Value & Normal Weight & Obese & $p$ Value \\
\hline Age (year) & $26 \pm 2$ & & & $29 \pm 1$ & $31 \pm 2$ & 0.426 \\
\hline BMI $\left(\mathrm{kg} / \mathrm{m}^{2}\right)$ & $24.9 \pm 1.5$ & $25.7 \pm 1.4$ & $0.004^{* *}$ & $22.4 \pm 0.5$ & $31.8 \pm 0.3$ & $0.001 * *$ \\
\hline Waist circumference $(\mathrm{cm})$ & $84.9 \pm 3.3$ & $86.9 \pm 3.3$ & $0.038 *$ & $83.6 \pm 1.7$ & $105 \pm 0.8$ & $0.001^{* *}$ \\
\hline hsCRP $(\mu \mathrm{g} / \mathrm{mL})$ & $0.6 \pm 0.1$ & $1.1 \pm 0.5$ & 0.38 & $1.96 \pm 0.01$ & $2.98 \pm 0.47$ & 0.036 * \\
\hline LPS (EU/mL) & $0.11 \pm 0.03$ & $0.16 \pm 0.10$ & 0.59 & $0.19 \pm 0.05$ & $0.18 \pm 0.04$ & 0.729 \\
\hline Lean mass (kg) & $57,3 \pm 2.5$ & $58.2 \pm 2.60$ & $0.032 *$ & - & - & \\
\hline Fat mass $(\mathrm{kg})$ & $15.8 \pm 2.9$ & $17.1 \pm 3.1$ & $0.048 *$ & - & - & \\
\hline Visceral fat (kg) & $66.0 \pm 18.1$ & $73.5 \pm 16.5$ & 0.469 & - & - & \\
\hline
\end{tabular}

\subsection{Postprandial Kinetics of LBP, sCD14 and IL-6 in Normal Weight and Obese Subjects (Lipinflox Study)}

We evaluated the postprandial variations of plasma LBP, sCD14 and IL-6 in NW and obese subjects during $5 \mathrm{~h}$ after mixed meals differing only by fat amount: $10 \mathrm{vs}$. $40 \mathrm{~g}$ of milkfat spread on bread.

Figure 1A,B shows that, regardless of lipid amount in the meal, the concentration of LBP in plasma was higher in obese subjects than in lean subjects (obese status, $p=0.027$ ), with no impact of postprandial time. No significant difference was observed between lean and obese subjects along the postprandial kinetics of sCD14, regardless of fat load in the meal (Figure 1C,D). 
Fat load: $10 \mathrm{~g}$

Fat load: $\mathbf{4 0} \mathrm{g}$

A
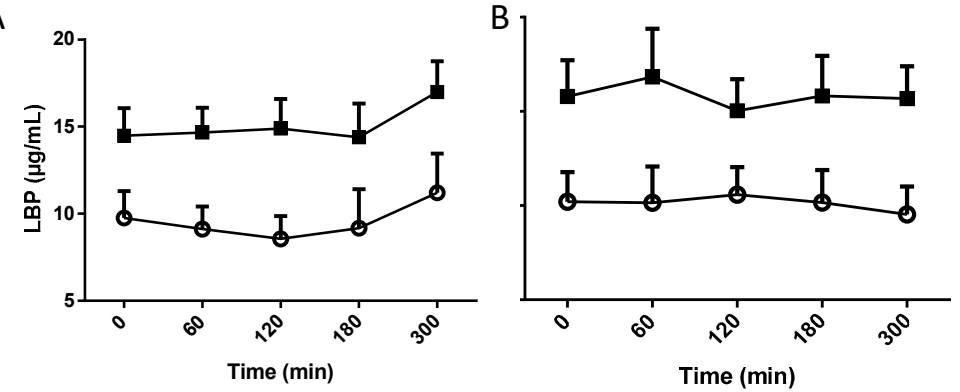

Time

$\begin{array}{ll}p & \boldsymbol{p}=\mathbf{0 . 0 2 7} \\ \text { Fat load } & p=0.140\end{array}$

Time:Ob. status $\quad p=0.870$

Time:Fat load $\quad p=0.700$

Ob. status:Fatload $\quad p=0.880$

Time:Ob. status:Fat load $p=0.987$

C

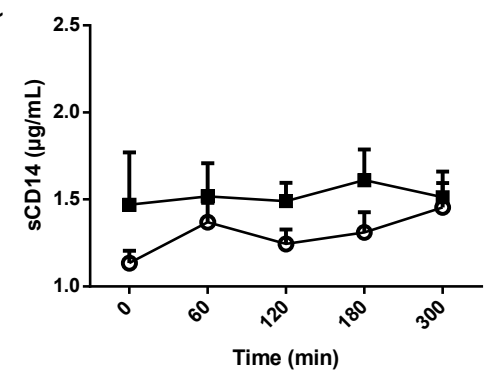

$E$

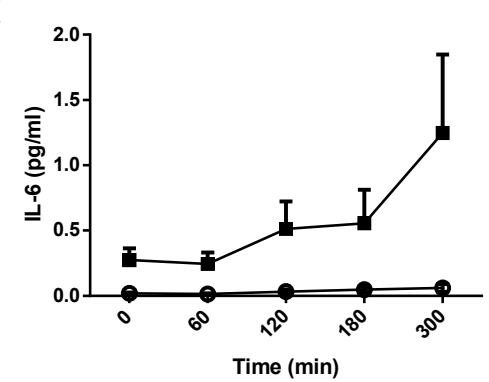

D

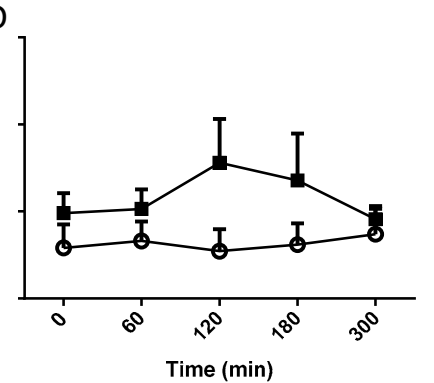

$\mathrm{F}$

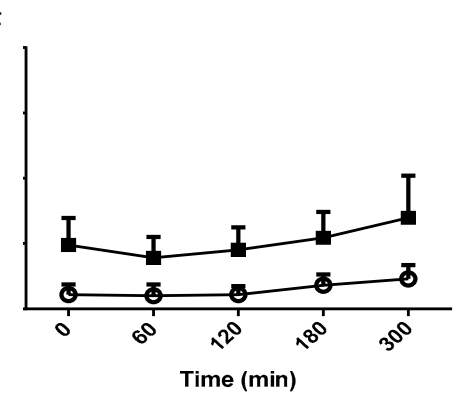

$\begin{array}{ll}\text { Time } & p=0.999 \\ \text { Obese status } & p=0.389 \\ \text { Fat load } & p=0.675 \\ \text { Time:Ob. status } & \boldsymbol{p}=\mathbf{0 . 0 1 2} \\ \text { Time:Fat load } & p=0.998 \\ \text { Ob. status:Fatload } & p=0.683 \\ \text { Time:Ob. status:Fat load } & p=0.302\end{array}$

Obese subjects

Lean subjects

Figure 1. Postprandial kinetics in plasma of lipopolysaccharides (LPS)-binding protein (LBP) (A,B); sCD14 (C,D); and Il-6 (E,F) in normal-weight and obese subjects after $10 \mathrm{~g}$ vs. $40 \mathrm{~g}$ fat load. Data are means \pm SEM. ${ }^{*} p<0.05$.

Regarding IL-6, we observed an interaction effect between time and obese status $(p=0.012)$ during the postprandial kinetics (Figure 1E,F). The post-hoc analysis revealed that the significant two-way interaction between obesity and time occurred mostly at $t=300 \mathrm{~min}$. Indeed, IL-6 plasma concentration at 300 min was on average 5.6 times higher in obese vs. lean men $(p=0.02)$ (Figure 1E).

There was no impact of BMI and postprandial time on the LBP/sCD14 ratio in all subjects for each fat amount (Appendix A).

\subsection{Postprandial Kinetics of LBP, sCD14 and IL-6 Before and After Overfeeding}

Previously, we have shown in 18 subjects of the OF clinical trial that the LBP/sCD14 ratio was enhanced in the fasting state after OF [14]. Here, we completed our exploration by analyzing the postprandial evolution of LBP, sCD14 and LBP/sCD14 in the subgroup of eight subjects who performed the postprandial explorations. Altogether, there was no significant effect of $O F$ on the postprandial kinetics of LBP and sCD14 (Figure 2A,B). Concerning LBP before OF, we observed a significant time effect with an increase of LBP concentration in plasma $120 \mathrm{~min}$ after the mixed meal (Figure 2A, $p<0.05$ ). The concentration of LBP was decreased at $240 \mathrm{~min}$ vs. $120 \mathrm{~min}$ (Figure $2 \mathrm{~A}, p<0.05$ ). After OF, no significant increase was observed at $120 \mathrm{~min}$ after the mixed meal but a significant decrease was observed at $240 \mathrm{~min}$ compared to $120 \mathrm{~min}(p<0.05)$. Notably, even if after OF LBP concentration was higher at fasting compared to before OF $(p=0.07)$, at $240 \mathrm{~min}$ LBP concentrations were similar before and after OF $(18.3 \pm 1.9 \mu \mathrm{g} / \mathrm{mL}$ and $18.2 \pm 0.8 \mu \mathrm{g} / \mathrm{mL}$, respectively). A significant increase of 
sCD14 at $240 \mathrm{~min}$ compared to 0 and $60 \min (p<0.01$ and 0.01 respectively) was observed both before and after OF (Figure 2B). The postprandial kinetics of the LBP/sCD14 ratio was not impacted by OF (Figure 2C). Both before and after OF, the LBP/sCD14 ratio decreased at $240 \mathrm{~min}(p<0.001$ vs. other postprandial times). We have measured IL-6 plasma concentration at 0, 120 and $240 \mathrm{~min}$ before and after OF (Figure 2D). There was no significant OF effect but of note, after OF plasma IL-6 concentration increased at $240 \mathrm{~min}$ compared to $0 \mathrm{~min}(p<0.05)$. No interaction (between time and $\mathrm{OF}$ ) was observed for LBP, sCD14, LBP/sCD14 and IL-6 (Figure 2A-D).

A
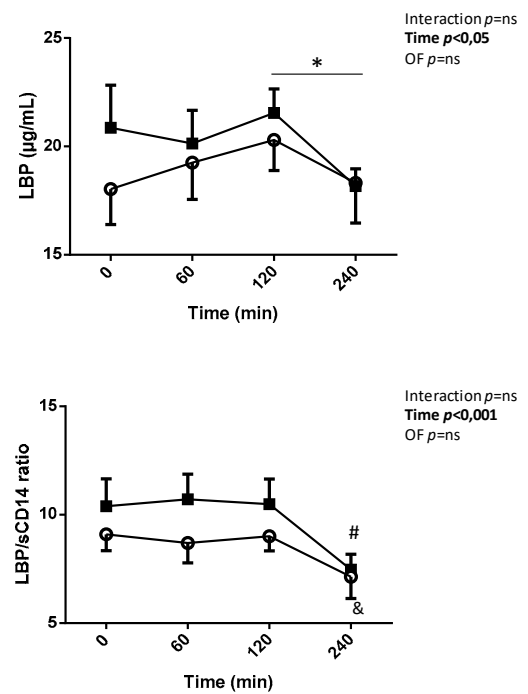

B

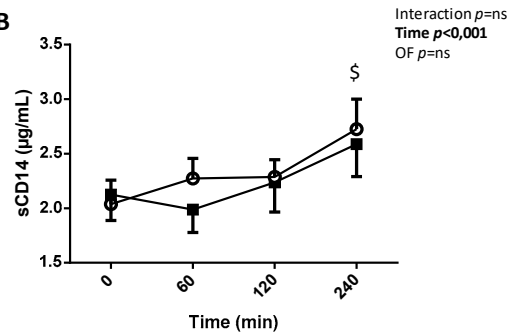

D

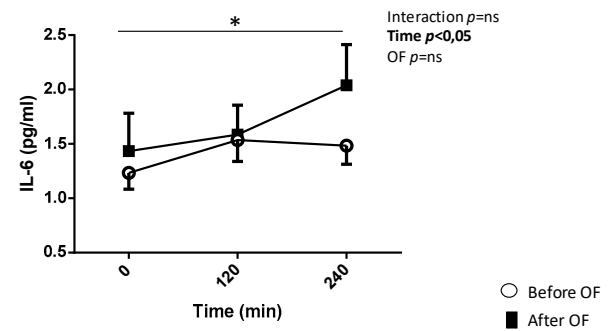

Figure 2. Postprandial kinetics of LBP (A), sCD14 (B), LBP/sCD14 ratio (C) and IL-6 (D) before and after overfeeding. Data are means \pm SEM. The effects of time (postprandial kinetics) and overfeeding (OF) were determined by ANOVA for repeated measurements followed by post hoc test (Bonferroni). ${ }^{*} p<0.05$ (after OF), \& $p<0.05$ vs. T0 and T120 (before OF); $p<0.001$ vs. other time (after OF); $\$ p<0.05 ; 0.01 ; 0.001$ vs. other time before and after OF.

\subsection{Associations between Fasting and Postprandial LBP and Selected Parameters of Dietary Trials and Intervention}

We examined the association of plasma LBP concentrations with some parameters related to obesity and metabolic disorders in subjects from both the overfeeding and Lipinflox studies. Subjects of the Lipinflox study who have consumed a test meal with $40 \mathrm{~g}$ of lipids presented no significant correlation between circulating LBP and the selected parameters, age, weight, BMI, waist circumference (WC), aspartame amino transferase (AST), alanine amino transferase (ALT), sCD14 (data not shown).

The correlations between LBP and selected parameters of the Lipinflox postprandial clinical trial after the test meal containing $10 \mathrm{~g}$ of fat are reported Table 2. At all times of the postprandial kinetics, the LBP concentration was significantly and positively associated with waist circumference (WC), but not with weight and BMI in all subjects from Lipinflox clinical trial (lean and obese, Table 2). After stratification according to BMI group, this positive correlation was maintained for lean subjects, but not for obese subjects (Table 2). LBP concentration was also significantly and positively associated with ALT but not with AST. These correlations were also maintained for lean subjects at 0,60 and $120 \mathrm{~min}$, a trend was observed at 180 and $300 \mathrm{~min}$ (Table 2). Conversely, no association of LBP with WC or with ALT was observed for obese subjects (Table 2).

Concerning the overfeeding clinical trial, we also used some mass parameters, such as abdominal visceral fat and subcutaneous WAT depots, measured by magnetic resonance imaging [27]. As shown in Table 3, LBP concentration in plasma was significantly and positively associated with trunk lean mass, lean mass and waist circumference before and after OF. No correlation with subject age was 
observed (data not shown). Notably, the LBP/sCD14 ratio was significantly and positively associated with lean mass, fat trunk and BMI, before and after overfeeding (Table 3).

Table 2. Correlation analyses (Spearman) with postprandial plasma LBP concentrations as dependent variable after a $10 \mathrm{~g}$ fat load (Lipinflox clinical trial in men). ${ }^{*} p<0.05 ;{ }^{* *} p<0.01$.

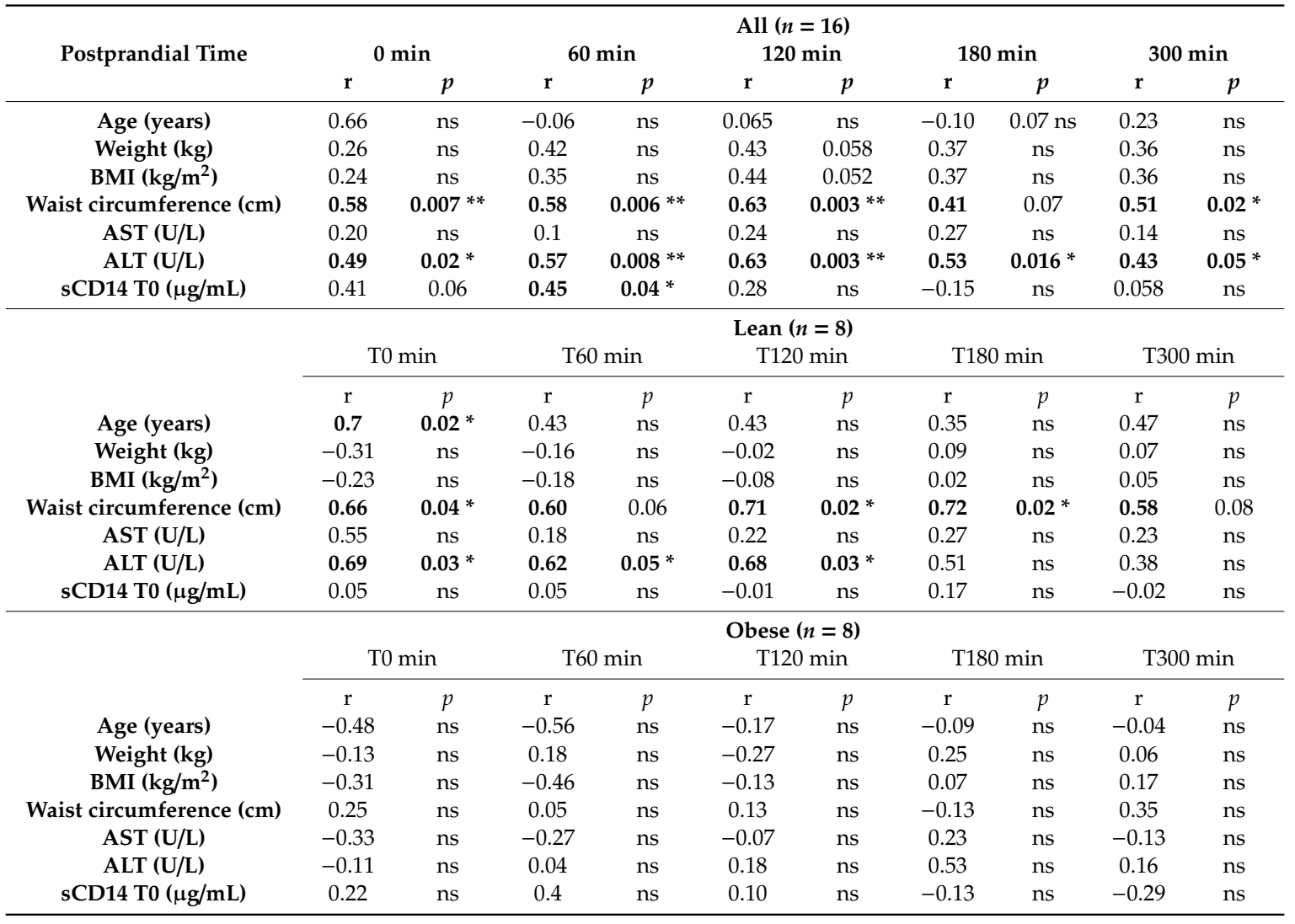

Table 3. Correlation analyses (Spearman) of fasting LBP and LBP/sCD14 with mass parameters in the overfeeding clinical trial $\left(n=18\right.$ men). ${ }^{*} p<0.05 ;{ }^{* *} p<0.01$.

\begin{tabular}{|c|c|c|c|}
\hline \multicolumn{4}{|c|}{ Before OF } \\
\hline Variable 1 & Variable 2 & $\mathbf{r}$ & $p$ \\
\hline \multirow{6}{*}{$\mathrm{LBP}(\mu \mathrm{g} / \mathrm{mL})$} & Trunk lean mas (kg) & 0.65 & $0.002 * *$ \\
\hline & Lean mass (kg) & 0.57 & $0.009^{* *}$ \\
\hline & Waist circumference $(\mathrm{cm})$ & 0.53 & $0.02 *$ \\
\hline & BMI $\left(\mathrm{kg} / \mathrm{m}^{2}\right)$ & 0.47 & $0.04 *$ \\
\hline & Fat trunk $(\mathrm{kg})$ & 0.41 & ns \\
\hline & Visceral fat (kg) & 0.52 & $0.03 *$ \\
\hline \multirow{3}{*}{$\mathrm{LBP} / \mathrm{sCD} 14$} & Lean mass (kg) & 0.62 & $0.004^{* *}$ \\
\hline & Fat trunk (kg) & 0.48 & $0.04 *$ \\
\hline & $\mathrm{BMI}\left(\mathrm{kg} / \mathrm{m}^{2}\right)$ & 0.62 & $0.004^{* *}$ \\
\hline \multicolumn{4}{|c|}{ After OF } \\
\hline Variable 1 & Variable 2 & $\mathrm{r}$ & $p$ \\
\hline \multirow{6}{*}{$\mathrm{LBP}(\mu \mathrm{g} / \mathrm{mL})$} & Trunk lean mas $(\mathrm{kg})$ & 0.62 & $0.003 * *$ \\
\hline & Lean mass (kg) & 0.56 & $0.01 *$ \\
\hline & Waist circumference $(\mathrm{cm})$ & 0.51 & $0.02 *$ \\
\hline & $\operatorname{BMI}\left(\mathrm{kg} / \mathrm{m}^{2}\right)$ & 0.32 & ns \\
\hline & Fat trunk (kg) & 0.47 & $0.04 *$ \\
\hline & Visceral fat (kg) & 0.07 & ns \\
\hline \multirow{3}{*}{ LBP/sCD14 } & Lean mass (kg) & 0.49 & $0.03 *$ \\
\hline & Fat trunk (kg) & 0.49 & $0.03 *$ \\
\hline & $\operatorname{BMI}\left(\mathrm{kg} / \mathrm{m}^{2}\right)$ & 0.49 & $0.03 *$ \\
\hline
\end{tabular}




\section{Discussion}

The novel feature of the present study is the postprandial explorations of LBP and sCD14 concentrations in plasma in two different clinical trials in obese vs. overweight and normal-weight men. In the first clinical trial (Lipinflox), we have shown that obese men presented a higher LBP concentration in plasma than lean men, regardless of fat load (10 g vs. $40 \mathrm{~g})$, with no time effect during the postprandial period. However, no significant differences in SCD14 concentrations were observed between lean and obese men. In the second clinical trial (overfeeding), we demonstrated, in lean to overweight men, a time effect on LBP, sCD14, IL-6 concentrations and LBP/sCD14 ratio during the postprandial period. Only a few human studies have focused on the effect of an OF on endotoxemia [24] and, to our knowledge, no study has been performed to date in order to evaluate the impact of dietary fat intake on the postprandial kinetics of LBP and SCD14 in NW, overweight and obese men.

It is now well established that the intestinal barrier function is modified in obesity, leading to low-grade inflammation and endotoxemia [9]. Endotoxins have been described as contributors to the inflammation observed in hypercaloric diets $[5,28,29]$. LBP and sCD14, two important actors in the endotoxin metabolic pathway, are now considered indirect markers of gut permeability in metabolic diseases, but also in other diseases, such as HIV [9,22]. Indeed, both reductions of these markers and gut permeability were shown after 12 weeks of fish oil supplementation, compared to placebo in HIV+ patients [30]. We show in the Lipinflox study that LBP concentration was higher in obese men at all times of the postprandial kinetics, independently of fat load (10 vs. $40 \mathrm{~g}$ of fat).

The relationship between inflammation and "metabolically healthy" and "non-metabolic healthy" status remains relatively unknown, even though some studies have shown relationships between inflammatory markers and obesity or metabolic syndrome. Aguilar-Salinas CA et al. demonstrated that obese individuals depict similar adiponectin levels to normal-weight subjects and this may be associated with the "metabolically healthy" obese phenotype [31]. In turn, patients with severe obesity were reported to have higher LBP concentration, which can be reduced after bariatric surgery [32]. In a recent study, it was suggested that serum LBP is related to abdominal obesity more than to metabolic health [16]. Serum LBP is also known to be associated with the carotid intima media thickness [19], suggesting that the pro-inflammatory action of LBP might be a contributor to the progression of cardiovascular events [11,33]. In hemodialysis patients, for whom gut barrier and microbiota are impaired, a positive association between LBP and chronic inflammation and metabolic syndrome was reported [34]. The present study shows a strong relationship between plasma LBP and waist circumference. It is interesting to note that plasma LBP was correlated significantly with WC only in lean subjects. Another point is the correlation of LBP with ALT only in lean subjects. Patients with non-alcoholic fatty liver disease are known to present higher LBP concentrations when they develop steatohepatitis [15]. An association between LBP and ALT was noted in hepatitis C virus, and these authors suggested that, as with ALT, LBP might serve as another hepatic inflammatory biomarker [35]. Another study has shown that endotoxemia reflects the hepatic functional reserve capacity of end-stage liver disease [36]. Interestingly, in obese subjects of the present study, no correlation of circulating LBP with WC or ALT was observed. Naghizadek et al., 2018 have shown that WC is important for the association among TLR4, serum LBP and IFN $\beta$ and metabolic state only for the highest WC range [16]. This finding is not in agreement with the present study, and could be explained by the fact that obese subjects were not morbid.

In the Lipinflox study, the fat load (10 vs. $40 \mathrm{~g}$ ) did not modify the kinetics of the LBP concentration in the plasma of lean and obese subjects. However, the LBP concentration in lean subjects was lower than that in obese subjects for both fat loads. Moreover, the dietary intervention in the OF study did not affect postprandial LBP concentrations. Umoh F. et al. also suggested that obesity might not result in enhanced exposure to intestinal bacteria, as the effect of BMI was no longer significant in multiple linear regression models [37]. It is well known that obesity is associated with modifications in the secretion of cytokines from adipose tissue and liver. However, only few studies have investigated the impact of 
overfeeding on the production of cytokines/adipokines. In the present OF study, the concentrations of LBP, sCD14 and Il-6 were not significantly affected by a two-month overfeeding (+760 kcal/day by adding $70 \mathrm{~g}$ of lipids to the usual daily diet). More precisely, the fat OF consisted in daily addition of $20 \mathrm{~g}$ of butter, $100 \mathrm{~g}$ of cheese (Emmental) and $40 \mathrm{~g}$ of almonds. Another study of acute overfeeding (+1250 kcal/day with a nutrient composition of $45 \%$ fat, $15 \%$ protein and $40 \%$ carbohydrate) has shown that 3 days are sufficient to increase body weight and HOMA-IR, without affecting MCP-1 and CRP plasma concentrations [38]. Tam C.S. et al. also demonstrated that moderate weight gain after 28 days of overfeeding (+1250 kcal via high-fat snacks composed of $45 \%$ fat, $15 \%$ protein, and $40 \%$ carbohydrate) in healthy humans resulted in a significant weight gain and increased circulating levels of CRP and MCP-1, without changes in subcutaneous WAT mass [39]. Those results demonstrate that different compositions of overfeeding diets may differentially impact cytokines/adipokine concentrations in plasma and tissues.

The present study has some limitations. Firstly, the sample size was small, owing the cumbersome aspects of postprandial explorations, and only one plasma inflammatory marker was measured. However, the postprandial results were obtained from two different trials, and the timing of plasma collection was not the same. Another limitation of this study is the measure of IL-6 in plasma taken serially from a catheter in an arm vein. Indeed some authors have shown that the presence of the catheter irritate the vein and cause an increase in IL-6 levels in plasma samples taken over several hours compared to fresh samples taken from the opposite arm $[40,41]$. Finally, ensuring adherence to dietary instructions given during the OF clinical trial is difficult in a feeding trial.

To conclude, we have shown in obese men that a fat load of $10 \mathrm{~g}$ of lipids can drive an increase of IL-6 concentration in plasma at 300 min post-meal, maybe due to a lesser clearance of LPS by lipoproteins. Indeed Vors et al. has shown that obese subject chylomicrons were more enriched with LPS compared to NW, which could contribute to LPS clearance and to a lesser IL-6 concentration in plasma [23]. This result should be confirmed in further studies with the measure of other inflammatory markers. The LBP concentration in plasma was higher in obese subjects than in NW subjects both at fasting and along the postprandial period (Lipinflox clinical trial), and was significantly and positively associated with trunk lean mass, lean mass and waist circumference before and after OF. Further studies are now necessary to better understand the relative role of LBP and SCD14 during the postprandial phase after diets containing different amounts and types of fats in different food matrixes.

Author Contributions: F.L., C.V., M.-C.M. did the conception and design of the research; F.L., C.V., M.A., G.P., J.D., B.M., S.L.-P., M.L., H.V. and M.-C.M. performed the experiments. F.L., C.V., C.K., M.-C.M. interpreted the results of the experiments; F.L., M.-C.M. prepared the figures and drafted the manuscript. F.L., C.V., M.-C.M. edited and revised the manuscript. All authors have read and agree to the published version of the manuscript.

Funding: This work was funded by the French National Research Agency (ANR), projects FLORINFLAM ANR-07-PNRA-0007 and METAPROFILE ANR-06-PNRA-0007. F.L. received a postdoctoral grant from INRA and a research grant from ALFEDIAM-SFD. M.-C.M. received financial support from INRA. C.V. received a PhD grant from INRA and CNIEL (French Dairy Interbranch Organization). The Lipinflox study was funded by CNIEL. The funding agencies had no role in the data analysis, interpretation and publication.

Acknowledgments: We gratefully thank all the volunteers for their involvement and the clinical teams of the CRNH-Rhône-Alpes and CRNH-Auvergne for their help in subjects' recruitment and metabolic explorations: J. Peyrat, C. Maitrepierre, N. Torche, M. Sothier, N. Feugier.

Conflicts of Interest: M.-C.M. received other research fundings on other topics from Sodiaal-Candia R\&D, the Centre National Interprofessionnel de l'Economie Laitière (CNIEL) and Nutricia Research and has consultancy activities for food \& dairy companies. These activities had no link with the present study. Other authors have no conflict of interest to disclose.

\section{Abbreviations}

ALT, alanine amino transferase; AST, aspartame amino transferase; LBP, lipopolysaccharides-binding protein; LPS, lipopolysaccharides; NW, normal weight; OF, overfeeding; sCD14, soluble cluster of differentiation; WAT, white adipose tissue; WC, waist circumference. 
Appendix A. Postprandial Kinetics of LBP/sCD14 after $10 \mathrm{~g}$ vs. 40 g Fat Load. Data Are Means \pm SEM

A

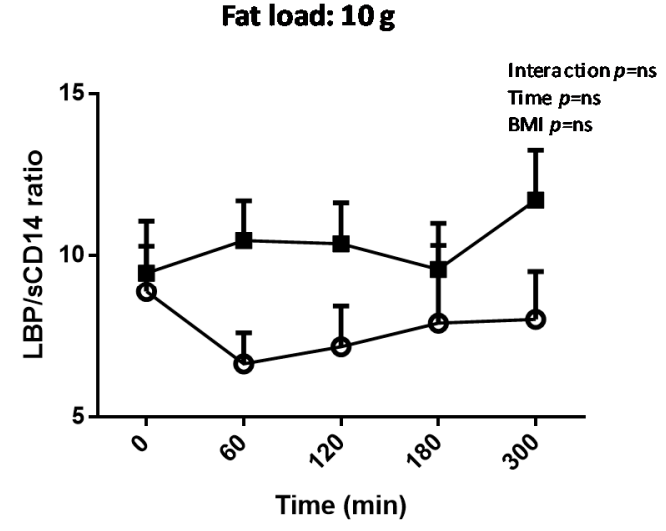

B Fat load: $\mathbf{4 0} \mathrm{g}$

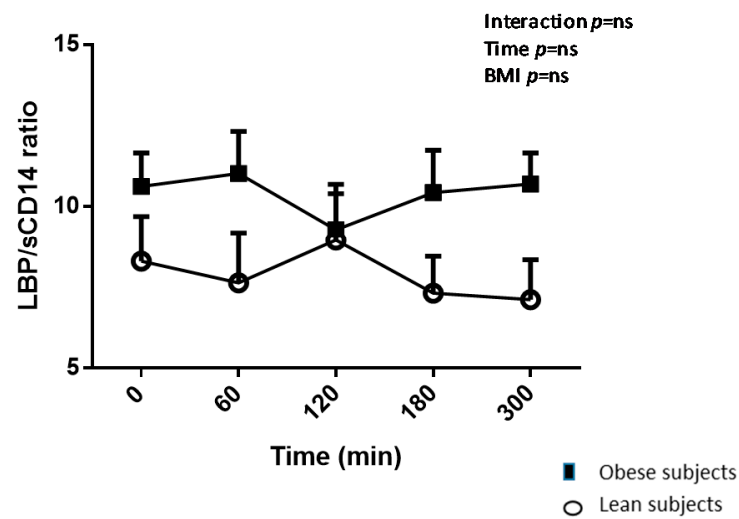

\section{References}

1. Hotamisligil, G.S. Inflammation and metabolic disorders. Nature 2006, 444, 860-867. [CrossRef] [PubMed]

2. Erridge, C.; Attina, T.; Spickett, C.M.; Webb, D.J. A high-fat meal induces low-grade endotoxemia: Evidence of a novel mechanism of postprandial inflammation. Am. J. Clin. Nutr. 2007, 86, 1286-1292. [CrossRef] [PubMed]

3. Ghoshal, S.; Witta, J.; Zhong, J.; de Villiers, W.; Eckhardt, E. Chylomicrons promote intestinal absorption of lipopolysaccharides. J. Lipid Res. 2009, 50, 90-97. [CrossRef] [PubMed]

4. Laugerette, F.; Vors, C.; Geloen, A.; Chauvin, M.A.; Soulage, C.; Lambert-Porcheron, S.; Peretti, N.; Alligier, M.; Burcelin, R.; Laville, M.; et al. Emulsified lipids increase endotoxemia: Possible role in early postprandial low-grade inflammation. J. Nutr. Biochem. 2011, 22, 53-59. [CrossRef] [PubMed]

5. Herieka, M.; Erridge, C. High-fat meal induced postprandial inflammation. Mol. Nutr. Food Res. 2014, 58, 136-146. [CrossRef]

6. Clemente-Postigo, M.; Queipo-Ortuno, M.I.; Murri, M.; Boto-Ordonez, M.; Perez-Martinez, P.; Andres-Lacueva, C.; Cardona, F.; Tinahones, F.J. Endotoxin increase after fat overload is related to postprandial hypertriglyceridemia in morbidly obese patients. J. Lipid Res. 2012, 53, 973-978. [CrossRef]

7. Hailman, E.; Lichenstein, H.S.; Wurfel, M.M.; Miller, D.S.; Johnson, D.A.; Kelley, M.; Busse, L.A.; Zukowski, M.M.; Wright, S.D. Lipopolysaccharide (LPS)-binding protein accelerates the binding of LPS to CD14. J. Exp. Med. 1994, 179, 269-277. [CrossRef]

8. Stoll, L.L.; Denning, G.M.; Weintraub, N.L. Potential role of endotoxin as a proinflammatory mediator of atherosclerosis. Arterioscler. Thromb. Vasc. Biol. 2004, 24, 2227-2236. [CrossRef]

9. Sun, L.; Yu, Z.; Ye, X.; Zou, S.; Li, H.; Yu, D.; Wu, H.; Chen, Y.; Dore, J.; Clement, K.; et al. A marker of endotoxemia is associated with obesity and related metabolic disorders in apparently healthy Chinese. Diabetes Care 2010, 33, 1925-1932. [CrossRef]

10. Gonzalez-Quintela, A.; Alonso, M.; Campos, J.; Vizcaino, L.; Loidi, L.; Gude, F. Determinants of serum concentrations of lipopolysaccharide-binding protein (LBP) in the adult population: The role of obesity. PLoS ONE 2013, 8, e54600. [CrossRef]

11. Lepper, P.M.; Schumann, C.; Triantafilou, K.; Rasche, F.M.; Schuster, T.; Frank, H.; Schneider, E.M.; Triantafilou, M.; von Eynatten, M. Association of lipopolysaccharide-binding protein and coronary artery disease in men. J. Am. Coll. Cardiol. 2007, 50, 25-31. [CrossRef] [PubMed]

12. Moreno-Navarrete, J.M.; Escote, X.; Ortega, F.; Camps, M.; Ricart, W.; Zorzano, A.; Vendrell, J.; Vidal-Puig, A.; Fernandez-Real, J.M. Lipopolysaccharide binding protein is an adipokine involved in the resilience of the mouse adipocyte to inflammation. Diabetologia 2015, 58, 2424-2434. [CrossRef] [PubMed]

13. Lakatos, P.L.; Kiss, L.S.; Palatka, K.; Altorjay, I.; Antal-Szalmas, P.; Palyu, E.; Udvardy, M.; Molnar, T.; Farkas, K.; Veres, G.; et al. Serum lipopolysaccharide-binding protein and soluble CD14 are markers of disease activity in patients with Crohn's disease. Inflam. Bowel Dis. 2011, 17, 767-777. [CrossRef] [PubMed] 
14. Laugerette, F.; Alligier, M.; Bastard, J.P.; Drai, J.; Chanseaume, E.; Lambert-Porcheron, S.; Laville, M.; Morio, B.; Vidal, H.; Michalski, M.C. Overfeeding increases postprandial endotoxemia in men: Inflammatory outcome may depend on LPS transporters LBP and sCD14. Mol. Nutr. Food Res. 2014, 58, 1513-1518. [CrossRef] [PubMed]

15. Ruiz, A.G.; Casafont, F.; Crespo, J.; Cayon, A.; Mayorga, M.; Estebanez, A.; Fernadez-Escalante, J.C.; Pons-Romero, F. Lipopolysaccharide-binding protein plasma levels and liver TNF-alpha gene expression in obese patients: Evidence for the potential role of endotoxin in the pathogenesis of non-alcoholic steatohepatitis. Obes. Surg. 2007, 17, 1374-1380. [CrossRef]

16. Naghizadeh, M.; Baradaran, B.; Saghafi-Asl, M.; Amiri, P.; Shanehbandi, D.; Karamzad, N.; Mohamed-Khosroshahi, L. Toll-like receptor signaling and serum levels of interferon beta and lipopolysaccharide binding protein are related to abdominal obesity: A case-control study between metabolically healthy and metabolically unhealthy obese individuals. Nutr. Res. 2018, 55, 11-20. [CrossRef]

17. Laugerette, F.; Furet, J.P.; Debard, C.; Daira, P.; Loizon, E.; Geloen, A.; Soulage, C.O.; Simonet, C.; Lefils-Lacourtablaise, J.; Bernoud-Hubac, N.; et al. Oil composition of high-fat diet affects metabolic inflammation differently in connection with endotoxin receptors in mice. Am. J. Physiol. Endocrinol. Metab. 2012, 302, E374-E386. [CrossRef]

18. Sakura, T.; Morioka, T.; Shioi, A.; Kakutani, Y.; Miki, Y.; Yamazaki, Y.; Motoyama, K.; Mori, K.; Fukumoto, S.; Shoji, T.; et al. Lipopolysaccharide-binding protein is associated with arterial stiffness in patients with type 2 diabetes: A cross-sectional study. Cardiovasc. Diabetol. 2017, 16, 62. [CrossRef]

19. Serrano, M.; Moreno-Navarrete, J.M.; Puig, J.; Moreno, M.; Guerra, E.; Ortega, F.; Xifra, G.; Ricart, W.; Fernandez-Real, J.M. Serum lipopolysaccharide-binding protein as a marker of atherosclerosis. Atherosclerosis 2013, 230, 223-227. [CrossRef]

20. Kheirandish-Gozal, L.; Peris, E.; Wang, Y.; Tamae Kakazu, M.; Khalyfa, A.; Carreras, A.; Gozal, D. Lipopolysaccharide-binding protein plasma levels in children: Effects of obstructive sleep apnea and obesity. J. Clin. Endocrinol. Metab. 2014, 99, 656-663. [CrossRef]

21. Kong, Y.; Li, Z.; Tang, T.; Wu, H.; Liu, J.; Gu, L.; Zhao, T.; Huang, Q. The level of lipopolysaccharide-binding protein is elevated in adult patients with obstructive sleep apnea. BMC Pulm. Med. 2018, 18, 90. [CrossRef] [PubMed]

22. de Buhr, M.F.; Hedrich, H.J.; Westendorf, A.M.; Obermeier, F.; Hofmann, C.; Zschemisch, N.H.; Buer, J.; Bumann, D.; Goyert, S.M.; Bleich, A. Analysis of Cd14 as a genetic modifier of experimental inflammatory bowel disease (IBD) in mice. Inflam. Bowel Dis. 2009, 15, 1824-1836. [CrossRef] [PubMed]

23. Vors, C.; Pineau, G.; Drai, J.; Meugnier, E.; Pesenti, S.; Laville, M.; Laugerette, F.; Malpuech-Brugere, C.; Vidal, H.; Michalski, M.C. Postprandial Endotoxemia Linked With Chylomicrons and Lipopolysaccharides Handling in Obese Versus Lean Men: A Lipid Dose-Effect Trial. J. Clin. Endocrinol. Metab. 2015, 100, 3427-3435. [CrossRef] [PubMed]

24. Pei, R.; DiMarco, D.M.; Putt, K.K.; Martin, D.A.; Chitchumroonchokchai, C.; Bruno, R.S.; Bolling, B.W. Premeal Low-Fat Yogurt Consumption Reduces Postprandial Inflammation and Markers of Endotoxin Exposure in Healthy Premenopausal Women in a Randomized Controlled Trial. J. Nutr. 2018, 148, 910-916. [CrossRef]

25. Alligier, M.; Meugnier, E.; Debard, C.; Lambert-Porcheron, S.; Chanseaume, E.; Sothier, M.; Loizon, E.; Hssain, A.A.; Brozek, J.; Scoazec, J.Y.; et al. Subcutaneous adipose tissue remodeling during the initial phase of weight gain induced by overfeeding in humans. J. Clin. Endocrinol. Metab. 2012, 97, E183-E192. [CrossRef] [PubMed]

26. Vors, C.; Drai, J.; Gabert, L.; Pineau, G.; Laville, M.; Vidal, H.; Guichard, E.; Michalski, M.C.; Feron, G. Salivary composition in obese vs normal-weight subjects: Towards a role in postprandial lipid metabolism? Int. J. Obes. (Lond.) 2015, 39, 1425-1428. [CrossRef] [PubMed]

27. Alligier, M.; Gabert, L.; Meugnier, E.; Lambert-Porcheron, S.; Chanseaume, E.; Pilleul, F.; Debard, C.; Sauvinet, V.; Morio, B.; Vidal-Puig, A.; et al. Visceral fat accumulation during lipid overfeeding is related to subcutaneous adipose tissue characteristics in healthy men. J. Clin. Endocrinol. Metab. 2013, 98, 802-810. [CrossRef] [PubMed]

28. Amar, J.; Burcelin, R.; Ruidavets, J.B.; Cani, P.D.; Fauvel, J.; Alessi, M.C.; Chamontin, B.; Ferrieres, J. Energy intake is associated with endotoxemia in apparently healthy men. Am. J. Clin. Nutr. 2008, 87, 1219-1223. [CrossRef] 
29. Zhang, J.; Wang, G.; Liu, J.; Gao, L.R.; Liu, M.; Wang, C.J.; Chuai, M.; Bao, Y.; Li, G.; Li, R.M.; et al. Gut microbiota-derived endotoxin enhanced the incidence of cardia bifida during cardiogenesis. J. Cell. Physiol. 2018, 233, 9271-9283. [CrossRef]

30. Fernandez-Real, J.M.; Perez del Pulgar, S.; Luche, E.; Moreno-Navarrete, J.M.; Waget, A.; Serino, M.; Sorianello, E.; Sanchez-Pla, A.; Pontaque, F.C.; Vendrell, J.; et al. CD14 modulates inflammation-driven insulin resistance. Diabetes 2011, 60, 2179-2186. [CrossRef]

31. Aguilar-Salinas, C.A.; Garcia, E.G.; Robles, L.; Riano, D.; Ruiz-Gomez, D.G.; Garcia-Ulloa, A.C.; Melgarejo, M.A.; Zamora, M.; Guillen-Pineda, L.E.; Mehta, R.; et al. High adiponectin concentrations are associated with the metabolically healthy obese phenotype. J. Clin. Endocrinol. Metab. 2008, 93, 4075-4079. [CrossRef]

32. Yang, P.J.; Lee, W.J.; Tseng, P.H.; Lee, P.H.; Lin, M.T.; Yang, W.S. Bariatric surgery decreased the serum level of an endotoxin-associated marker: Lipopolysaccharide-binding protein. Surg. Obes. Relat. Dis. Off. J. Am. Soc. Bariatr. Surg. 2014, 10, 1182-1187. [CrossRef] [PubMed]

33. Lepper, P.M.; Kleber, M.E.; Grammer, T.B.; Hoffmann, K.; Dietz, S.; Winkelmann, B.R.; Boehm, B.O.; Marz, W. Lipopolysaccharide-binding protein (LBP) is associated with total and cardiovascular mortality in individuals with or without stable coronary artery disease-Results from the Ludwigshafen Risk and Cardiovascular Health Study (LURIC). Atherosclerosis 2011, 219, 291-297. [CrossRef] [PubMed]

34. Lim, P.S.; Chang, Y.K.; Wu, T.K. Serum Lipopolysaccharide-Binding Protein is Associated with Chronic Inflammation and Metabolic Syndrome in Hemodialysis Patients. Blood Purif. 2019, 47, 28-36. [CrossRef] [PubMed]

35. Nien, H.C.; Hsu, S.J.; Su, T.H.; Yang, P.J.; Sheu, J.C.; Wang, J.T.; Chow, L.P.; Chen, C.L.; Kao, J.H.; Yang, W.S. High Serum Lipopolysaccharide-Binding Protein Level in Chronic Hepatitis C Viral Infection Is Reduced by Anti-Viral Treatments. PLoS ONE 2017, 12, e0170028. [CrossRef] [PubMed]

36. Okada, N.; Sanada, Y.; Urahashi, T.; Ihara, Y.; Yamada, N.; Hirata, Y.; Katano, T.; Otomo, S.; Ushijima, K.; Mizuta, K. Endotoxin Metabolism Reflects Hepatic Functional Reserve in End-Stage Liver Disease. Transplant. Proc. 2018, 50, 1360-1364. [CrossRef]

37. Umoh, F.I.; Kato, I.; Ren, J.; Wachowiak, P.L.; Ruffin, M.T.; Turgeon, D.K.; Sen, A.; Brenner, D.E.; Djuric, Z. Markers of systemic exposures to products of intestinal bacteria in a dietary intervention study. Eur. J. Nutr. 2016, 55, 793-798. [CrossRef]

38. Chen, M.; Liu, B.; Thompson, C.H.; Wittert, G.A.; Heilbronn, L.K. Acute Overfeeding Does Not Alter Liver or Adipose Tissue-Derived Cytokines in Healthy Humans. Ann. Nutr. Metab. 2016, 69, 165-170. [CrossRef]

39. Tam, C.S.; Viardot, A.; Clement, K.; Tordjman, J.; Tonks, K.; Greenfield, J.R.; Campbell, L.V.; Samocha-Bonet, D.; Heilbronn, L.K. Short-term overfeeding may induce peripheral insulin resistance without altering subcutaneous adipose tissue macrophages in humans. Diabetes 2010, 59, 2164-2170. [CrossRef]

40. Dixon, N.C.; Hurst, T.L.; Talbot, D.C.; Tyrrell, R.M.; Thompson, D. Active middle-aged men have lower fasting inflammatory markers but the postprandial inflammatory response is minimal and unaffected by physical activity status. J. Appl. Physiol. 2009, 107, 63-68. [CrossRef]

41. Thompson, D.; Dixon, N. Measurement of postprandial interleukin-6 via a catheter: What does it tell us? Eur. J. Appl. Physiol. 2009, 107, 621-622. [CrossRef] [PubMed]

(C) 2020 by the authors. Licensee MDPI, Basel, Switzerland. This article is an open access article distributed under the terms and conditions of the Creative Commons Attribution (CC BY) license (http://creativecommons.org/licenses/by/4.0/). 